\title{
ANÁLISE DA ESTRUTURA DO MERCADO BRASILEIRO DE CARROS POPULARES, 1990-2005
}

\author{
Leonardo Bornacki de Mattos ${ }^{l}$ \\ Áther de Miranda Barros ${ }^{2}$
}

\begin{abstract}
Resumo - Neste trabalho, objetivou-se analisar a evolução da estrutura do mercado brasileiro de carros populares no período de 1990 a 2005 . Foram utilizadas informações sobre número de unidades vendidas por cada firma no mercado interno, para determinação das respectivas parcelas de mercado, das taxas de concentração e do índice de Herfindahl-Hirschman. Os resultados indicaram que, apesar de ter ocorrido redução na concentração desse mercado ao longo do período analisado, este ainda se encontra fortemente concentrado, em níveis considerados pela Secretaria de Acompanhamento Econômico (SEAE) e pela Secretaria de Defesa Econômica (SDE) como suficientes para o exercício do poder coordenado de mercado.
\end{abstract}

Palavras-chave: organização industrial, estrutura de mercado, carros populares.

\section{Introdução}

O Brasil tem ocupado posição de destaque na produção mundial de veículos automotores. Em 2003, de acordo com dados da Associação Nacional dos Fabricantes de Veículos Automotores (Anfavea, 2005a), foi o décimo maior produtor mundial, tendo produzido 1,83 milhão de unidades, incluindo a produção de automóveis, de comerciais leves e comerciais pesados. Esse número foi cerca de 11 vezes maior que a produção da Argentina, segundo maior fabricante na América do Sul. Em termos mundiais, os Estados Unidos lideram o ranking, com produção anual superior a 12 milhões de unidades.

\footnotetext{
Doutorando em Economia Aplicada pelo Departamento de Economia Rural da Universidade Federal de Viçosa. E-mail: leobornacki@yahoo.com.br

2 Mestre em Economia Aplicada pelo Departamento de Economia Rural da Universidade Federal de Viçosa. E-mail: ather@bol.com.br
} 
Em 2003, a indústria automobilística brasileira atingiu um faturamento de US $\$ 18,05$ bilhões, o que representou 10,6\% do PIB industrial brasileiro. Desse total, US\$ 15,67 bilhões foram referentes ao segmento de veículos automotores e US\$2,38 bilhões ao segmento de máquinas agrícolas automotrizes. No ano de 2004, a balança comercial do setor apresentou saldo de US\$ 6,81 bilhões. Em 31 de dezembro desse mesmo ano, a indústria automobilística brasileira foi responsável por 101.989 empregos diretos, excluindo os decorrentes de atividades terceirizadas (Anfavea, 2005a).

Durante a década de 1990, muitas mudanças ocorreram na indústria automobilística brasileira. A abertura da economia, no início da década, foi um dos fatores mais relevantes na determinação de tais mudanças. A primeira medida adotada para "exposição" do setor automobilístico ao mercado externo foi a eliminação das barreiras não-tarifárias em 1990. Iniciou-se, em fevereiro de 1991, um cronograma de redução tarifária em quatro fases, que esteve presente até dezembro de 1994. Entretanto, em fevereiro de 1992, o cronograma foi alterado e as datas previstas para redução tarifária foram antecipadas.

A partir de fevereiro de 1995, a abertura foi revertida. A alíquota do Imposto de Importação, que, em setembro de 1994, era de 20\%, foi elevada pelo Decreto 1.427/95, do Ministério da Fazenda, para 32\%, alcançando o valor de 70\% em março desse mesmo ano. Em janeiro de 1997, a alíquota era de 63\%, apenas dois pontos percentuais a menos que seu valor em janeiro de 1990.

Apesar da redução da alíquota do Imposto de Importação, que ocorreu até setembro de 1994, um efeito significativo da abertura da economia brasileira sobre os preços dos veículos no mercado doméstico só foi observado em meados de 1993, já no final do cronograma de redução tarifária.

A tendência de queda nos preços dos veículos no mercado doméstico foi interrompida somente ao final de 1995, principalmente em decorrência da reversão do processo de abertura comercial por meio da elevação da 
alíquota de importação para 70\%, em março de 1995, e pela implantação do regime automotivo.

Em 1993, surgiu na indústria automobilística brasileira um novo segmento na produção de veículos automotores, que ficaria conhecido como o segmento dos carros populares. O então presidente Itamar Franco manifestou seu descontentamento com a inexistência de veículos que pudessem ser vendidos a preços populares. Sob isenção do Imposto sobre Produtos Industrializados (IPI) para veículos de mil cilindradas, a Volkswagen (VW) trouxe de volta ao mercado o Fusca. Em resposta, os demais fabricantes ofereceram modelos a preços populares (aproximadamente US\$ 7.000,003), o que resultou em grande expansão nas vendas desse tipo de produto.

As vendas internas dos carros populares cresceram significativamente. No ano de 1990, a participação de veículos de mil cilindradas no total de automóveis vendidos foi de 10,4\%; em julho de 2002, chegou a representar $75 \%$, fechando o ano de 2004 com 57,3\% das vendas internas de automóveis.

Segundo Negri (1998), essa crescente participação do carro popular nas vendas internas de automóveis foi seguida por constante aumento nos seus preços reais. Nos anos de 1994 a 1996, os preços dos carros populares tiveram aumentos reais de, aproximadamente, 16,65\%, enquanto as outras categorias tiveram queda de preços reais em torno de $21,13 \%$. O preço do carro popular praticamente dobrou em dez anos.

A respeito da relação entre os preços dos veículos e a quantidade demandada, alguns estudos mostraram que a demanda de veículos geralmente é preço-inelástica ${ }^{4}$. Esse resultado indica que, tudo mais constante, os vendedores de automóveis não teriam incentivos para reduzir o preço de seus produtos, uma vez que suas receitas seriam reduzidas mais que proporcionalmente à redução dos preços. Ao contrário,

Valor vigente no ano de 1993 .

4 Alguns estudos citados por Negri (1998) são: Levinsohn (1988), McCarthy (1996) e Coates (1985). 
seriam estimulados à elevação dos preços, já que a quantidade demandada decresceria menos que proporcionalmente.

Tendo em vista que os preços do setor não são "controlados" pelo governo, a existência de concorrência entre as firmas no mercado seria um dos poucos elementos capazes de limitar o aumento nos preços reais ou até mesmo provocar sua redução. É possível imaginar que, para conquistar maior parcela de mercado, uma firma tenha reduzido seu preço em algum momento. Da mesma forma, é possível que as firmas tenham optado por cooperarem entre si e elevarem conjuntamente os preços. Esse fato parece ter realmente ocorrido no mercado de carros populares, visto que foi o único segmento do setor automobilístico a sofrer aumentos de preços reais.

Segundo Aguiar (2003), a cooperação entre as firmas é mais provável em mercados mais concentrados, pelo fato de elas se conscientizarem das vantagens da ação conjunta ${ }^{5}$. De acordo com esse autor, essa relação decorreria do modelo de Chamberlin, que admite a existência de um nível crítico de concentração a partir do qual há reconhecimento de interdependência por parte das firmas. Em mercados pouco concentrados, haveria dificuldades de se obter a concordância para a ação conjunta.

Dada a importância assumida pelo segmento de carros populares na indústria automobilística brasileira ao longo da década de 1990, bem como a possibilidade de a distribuição do mercado entre as firmas ter influenciado a elevação dos preços reais, o objetivo deste trabalho foi analisar a evolução da estrutura do mercado brasileiro de carros populares no período de 1990 a 2005. Ressalta-se, ainda, o fato de não haver estudos que tenham realizado a análise proposta neste trabalho.

Especificamente, pretendeu-se estudar a concentração do referido mercado por meio da determinação das parcelas de mercado de cada

\footnotetext{
Os critérios adotados pela Secretaria de Acompanhamento Econômico (SEAE) e pela Secretaria de Defesa Econômica (SDE) para avaliar os atos de concentração consideram que um CR4 (soma da parcela de mercado das quatro maiores firmas) igual a $75 \%$ seria suficiente para o exercício coordenado de poder de mercado (Aguiar, 2003)
} 
firma, do cálculo das taxas de concentração CR2 e CR3, além do índice sumário de Herfindahl-Hirschman. Apesar de este trabalho ter enfatizado a análise da concentração de mercado, também foram feitas algumas considerações acerca da presença de barreiras à entrada de novas firmas no mercado.

\section{Metodologia}

\subsection{Referencial teórico 6}

O referencial teórico utilizado neste trabalho, para análise da estrutura do mercado de carros populares no Brasil, baseou-se na Teoria da Organização Industrial, especificamente na abordagem metodológica conhecida como Estrutura-Conduta-Desempenho (ECD). Na sua forma mais simples, a ECD considera que a estrutura do mercado determina o comportamento das firmas que nele atuam e o comportamento das firmas, o desempenho do mercado.

O primeiro passo para análise da estrutura de um mercado é a determinação do mercado ${ }^{7}$, que existe em basicamente duas dimensões: tipo de produto e dimensão geográfica.

Na primeira dimensão, são considerados no mesmo mercado produtos que são substitutos próximos. Tecnicamente, a substitutibilidade entre dois produtos é medida pela elasticidade cruzada da demanda entre eles. Entretanto, tal critério não tem tido utilidade prática, dada a dificuldade de se estabelecer uma medida precisa da elasticidade. Outros indicadores têm sido utilizados na determinação do mercado por "tipo de produto", como características e usos dos produtos; conhecimento dos participantes do mercado, especialmente dos produtores e vendedores; diferenciação entre grupos, tanto de vendedores como de compradores; e preço dos produtos, especificamente quanto a similaridades e tendências.

Esse item é baseado principalmente em Shepherd (1999)

"Um mercado é um grupo de compradores e vendedores que trocam bens que são fortemente substituíveis entre si." (Shepherd, 1999). 
Na segunda dimensão, são considerados no mesmo mercado os produtos comercializados numa mesma localização, sendo esta uma cidade, estado, país, etc. A extensão geográfica tem sido também indicada por outras evidências, como razão custo de transporte/preço e padrões ou distância de suprimento do produto.

Após a definição do mercado, torna-se possível uma análise dos principais elementos da sua estrutura. Segundo Shepherd (1999), os três principais elementos são: a firma com maior parcela de mercado, a qual pode ser uma firma dominante, média ou até mesmo pequena; a concentração do mercado, ou seja, a sua distribuição entre as firmas participantes; e as condições à entrada de novas firmas no mercado, ou, em outras palavras, a presença de barreiras à entrada. Outros autores, como Martin (1993) e Aguiar (2003), consideraram a diferenciação do produto como elemento da estrutura de mercado.

A distribuição do mercado entre as firmas é o elemento da estrutura que tem sido mais explorado em trabalhos empíricos, uma vez que a parcela de mercado de cada firma é o melhor indicador do poder de monopólio que pode ser exercido por ela. Além disso, conforme Aguiar (2003), a distribuição do mercado é o elemento de estrutura que possui maior facilidade de ser medido, sendo as parcelas de mercado e os índices de concentração as formas mais comuns de realizar tais medidas.

Entre as variáveis freqüentemente utilizadas na determinação da parcela de mercado de cada firma estão o valor monetário das vendas, a quantidade vendida por cada firma, a capacidade produtiva e, por último, o número de empregados (Aguiar, 2003).

A concentração de mercado é dada pela combinação das parcelas de mercado das principais firmas, geralmente sendo consideradas as quatro maiores. Um mercado em que poucas firmas detêm, conjuntamente, parcela significativa é oligopolizado e permite que tais firmas coordenem suas ações para atuarem similarmente a um monopolista. 
$\mathrm{O}$ conhecimento da parcela de mercado das principais firmas permite a classificação do tipo de mercado que estiver sendo analisado. De acordo com os critérios adotados por Shepherd (1999), um mercado será classificado como um oligopólio forte se a soma das parcelas de mercado das quatro maiores firmas for superior a $60 \%$ do mercado. Se o valor dessa soma for inferior a 40\%, o mercado será classificado como um oligopólio fraco. Valores entre $40 \%$ e $60 \%$ indicam que o mercado em questão é um oligopólio moderado ou intermediário.

As barreiras à entrada são os elementos que dificultam e até mesmo impedem a entrada de novas firmas no mercado, o que permite que as firmas que já se encontram estabelecidas possam agir de maneira monopolística, sem permitir a entrada de concorrentes potenciais.

As barreiras podem ter origem exógena ou endógena. Fontes exógenas estão relacionadas com características específicas do mercado e não podem ser controladas apenas pelas firmas líderes de mercado, como é o caso da tecnologia, da natureza dos produtos, da necessidade de capital em grande escala, da existência de economias de escala e de custos irrecuperáveis (sunk-costs), entre outras.

Por sua vez, as barreiras endógenas são geralmente criadas por ações das firmas líderes, com vistas a dificultar ou impedir a entrada de novos concorrentes. Esse tipo de barreira reflete o grau de imperfeição do mercado, de forma que mercados mais imperfeitos, freqüentemente, apresentam maiores barreiras à entrada. Alguns exemplos desse tipo de barreira são o excesso de capacidade ociosa mantido pelas firmas, a criação de patentes, os elevados gastos com promoções e propaganda, etc.

Entretanto, Shepherd (1999) reconheceu a extrema dificuldade de serem estimadas medidas representativas das barreiras à entrada. Para esse autor, quanto maior for a necessidade de capital para uma firma ingressar no mercado, maiores serão as barreiras. 


\subsection{Modelo analítico}

A análise da estrutura do mercado brasileiro de carros populares enfatizou a distribuição do mercado entre as firmas, no período de 1990 a 2005.

A parcela de mercado de uma firma $i$ qualquer, que é um importante indicador de seu poder dentro do mercado, é medida da seguinte forma:

$$
s_{i}=\frac{q_{i}}{\sum_{j=1}^{N} q_{j}}
$$

em que:

$s_{i}=$ parcela de mercado da firma $i$

$q_{i}=$ venda total (ou outra variável) da firma $i$;

$q_{j}=$ venda total (ou outra variável) da firma $j$; e

$\mathrm{N}$ = número de firmas no mercado.

A partir da determinação da parcela de mercado de cada uma das firmas, foi possível analisar a concentração do mercado por meio do cálculo da taxa de concentração (CRk), bem como do índice sumário de HerfindahlHirschman (HHI). A taxa de concentração das k maiores firmas do mercado é dada por:

$$
C R k=\sum_{i=1}^{k} s_{i}
$$

em que CRk é a taxa de concentração das k-ésimas maiores firmas do mercado, e $s_{i}$, a parcela de mercado da firma $i$. 
As vantagens da utilização de taxas de concentração são a simplicidade no cálculo destas, assim como a necessidade de informações apenas das k-ésimas maiores firmas, além de apresentarem uma idéia bastante clara do grau de monopolização de um mercado (Aguiar, 2003). Dentre suas deficiências, destaca-se o fato de um mesmo CRk representar estruturas diferentes. Ademais, a taxa de concentração não faz nenhuma referência ao número total de firmas e seus respectivos tamanhos e não considera a mudança de posição das firmas (turnover), o que indicaria um mercado mais competitivo.

A outra medida da concentração de mercado, utilizada neste trabalho, foi o índice sumário de Herfindahl-Hirschman (HHI), calculado da seguinte forma:

$$
H H I=\sum_{i=1}^{N} s_{i}^{2}
$$

em que $s_{i}$ é a parcela decimal (ou percentual) de mercado de cada uma das firmas.

A utilização da parcela decimal de mercado implica índice HHI, que varia de zero a um ${ }^{8}$. Na presença de monopólio, o índice será igual a um, já que a parcela da única firma no mercado também será um. À medida que aumenta o número de firmas no mercado, o índice HHI diminui. Caso existam "N" firmas iguais, ou seja, com parcelas iguais de mercado, o valor deste índice será igual a $1 / \mathrm{N}$. Outro ponto importante desse índice é o fato de que maiores desigualdades entre as firmas tornarão maior o índice HHI.

\footnotetext{
8 A utilização das parcelas na forma percentual implica índice HHI, que varia de zero a dez mil, sendo este o caso do monopólio (Aguiar, 2003).
} 


\subsection{Fonte de dados}

Os dados usados no cálculo das parcelas de mercado de cada uma das firmas, bem como da taxa de concentração $\mathrm{CRk}$, foram coletados na Anfavea (2004 e 2005b). Esses dados são referentes ao número de automóveis de mil cilindradas vendidos no mercado interno brasileiro. Os valores relativos ao ativo total e ao ativo permanente do setor de fabricação e montagem de veículos foram obtidos da Conjuntura Econômica (2003) e utilizados como referência da necessidade de capital por parte das firmas.

\section{Resultados e discussões}

A análise iniciou-se com a determinação do mercado de carros populares, segundo duas dimensões: tipo de produto e dimensão geográfica, conforme sugerido por Shepherd (1999).

$\mathrm{Na}$ primeira dimensão, foram considerados nesse mercado todos os veículos automotores equipados com motores de mil cilindradas, independentemente de outras características apresentadas, como consumo de combustível, potência do motor, componentes e acessórios opcionais. Para isso, considerou-se que tais características são implementadas por cada um dos fabricantes, visando, sobretudo, à diferenciação do produto.

Na dimensão geográfica, considerou-se que o mercado de carros populares abrangia todo o território brasileiro. Em todos os estados do país são encontrados concessionários (pontos de vendas) das quatro maiores empresas. Apesar de as empresas concentrarem suas unidades produtivas em apenas alguns estados do país, principalmente nas regiões Sul e Sudeste, o produto por elas vendido apresenta algumas características que permitem sua distribuição por todo o território nacional, como a baixa razão custo de transporte/preço do produto e o fato de não se tratar de um produto perecível. 
A parcela de mercado de cada firma foi determinada pelo número de unidades vendidas no mercado interno brasileiro, no período de 1990 a 2005. As primeiras unidades foram vendidas pela Fiat Automóveis em 1990, num total de 23.013 veículos, sendo esta empresa única no mercado até o ano seguinte. Em 1992, a General Motors do Brasil (GMB) e a Volkswagen (VW) entraram no mercado, embora com participação consideravelmente inferior à da Fiat.

Em 1993, mais uma empresa, a Ford, deu início à produção e à comercialização de veículos populares no Brasil, completando um total de quatro firmas no mercado. A entrada de outras duas firmas só ocorreu no ano de 1999, com a Renault, e no ano de 2001, com a Peugeot.

A evolução das vendas, desde a produção do primeiro modelo de mil cilindradas (o Uno Mille, da Fiat) no ano de 1990 até o ano de 2005, está apresentada na Tabela 1. 
Tabela 1 - Número de automóveis de mil cilindradas vendidos no mercado interno brasileiro, 1990-2005

\begin{tabular}{ccccccc}
\hline Ano & Fiat & GMB & VW & Ford & Outros & TOTAL \\
\hline 1990 & 23.013 & - & - & - & - & 23.013 \\
1991 & 67.292 & - & - & - & - & 67.292 \\
1992 & 63.523 & 19.812 & 9.238 & - & - & 92.573 \\
1993 & 119.675 & 30.240 & 83.000 & 9.049 & - & 241.964 \\
1994 & 203.708 & 54.148 & 144.879 & 45.132 & - & 447.867 \\
1995 & 232.750 & 118.817 & 174.556 & 69.722 & - & 595.845 \\
1996 & 298.101 & 144.549 & 196.876 & 61.914 & - & 701.440 \\
1997 & 324.058 & 163.951 & 256.710 & 127.154 & - & 871.873 \\
1998 & 228.806 & 148.137 & 226.473 & 99.511 & - & 702.927 \\
1999 & 217.171 & 124.722 & 203.486 & 58.057 & 2.199 & 605.635 \\
2000 & 253.777 & 175.029 & 240.693 & 64.590 & 20.330 & 754.419 \\
2001 & 291.841 & 216.047 & 272.631 & 56.375 & 41.366 & 878.260 \\
2002 & 246.360 & 218.356 & 199.514 & 77.274 & 60.365 & 801.869 \\
2003 & 220.923 & 200.775 & 147.236 & 78.689 & 52.303 & 699.926 \\
2004 & 212.944 & 215.482 & 185.432 & 86.471 & 41.233 & 741.562 \\
2005 & 244.851 & 244.851 & 211.403 & 197.545 & 78.532 & 763.084 \\
\hline
\end{tabular}

Fonte: Anfavea (2004, 2005b).

Com base no número de unidades vendidas por cada uma das firmas, foi determinada sua parcela de mercado, o que permitiu uma análise mais apurada da maneira como o mercado esteve distribuído entre as firmas ao longo do período estudado. Os resultados encontram-se na Tabela 2. 
Tabela 2 - Parcela de mercado (em \%) das firmas no mercado brasileiro de automóveis de mil cilindradas, 1990-2005

\begin{tabular}{cccccc}
\hline Ano & Fiat & GMB & VW & Ford & Outros \\
\hline 1990 & 100,00 & - & - & - & - \\
1991 & 100,00 & - & - & - & - \\
1992 & 68,62 & 21,40 & 9,98 & - & - \\
1993 & 49,46 & 12,50 & 34,30 & 3,74 & - \\
1994 & 45,48 & 12,09 & 32,35 & 10,08 & - \\
1995 & 39,06 & 19,94 & 29,30 & 11,70 & - \\
1996 & 42,50 & 20,61 & 28,07 & 8,83 & - \\
1997 & 37,17 & 18,80 & 29,44 & 14,58 & - \\
1998 & 32,55 & 21,07 & 32,22 & 14,16 & - \\
1999 & 35,86 & 20,59 & 33,60 & 9,59 & 0,36 \\
2000 & 33,64 & 23,20 & 31,90 & 8,56 & 2,69 \\
2001 & 33,23 & 24,60 & 31,04 & 6,42 & 4,71 \\
2002 & 30,72 & 27,23 & 24,88 & 9,64 & 7,53 \\
2003 & 31,56 & 28,68 & 21,04 & 11,24 & 7,48 \\
2004 & 28,72 & 29,06 & 25,01 & 11,66 & 5,56 \\
2005 & 32,09 & 27,70 & 25,89 & 10,29 & 4,03 \\
\hline
\end{tabular}

Fonte: Resultados da pesquisa.

De acordo com a Tabela 2, pode-se observar que, mesmo após a entrada de novas firmas, embora em pequeno número, a Fiat manteve, exceto no ano de 2004, a maior parcela do mercado brasileiro de veículos populares. Entretanto, essa empresa deixou a condição de monopolista por ela exercida nos anos de 1990 e 1991, quando era única no mercado, para deter, ao final de 2005, parcela equivalente a cerca de um terço do mercado.

Ao longo do período de 1990 a 2005, as empresas que mais aumentaram sua participação foram a Volkswagen (VW), que passou de 9,98\% em 1992 para 25,89\% em 2005, e a General Motors do Brasil (GMB), que saltou para $27,70 \%$ em 2005 . No decorrer desse mesmo período, a Ford 
sempre se manteve como a quarta maior empresa, com parcela pouco superior a $10 \%$ em 2005.

Outra característica desse mercado é o baixo turnover, ou seja, quase não se verifica troca de posições entre as firmas, o que indica ser ele um mercado pouco competitivo. Esse fato pode ser comprovado na Figura 1, que apresenta a evolução da parcela de mercado das quatro maiores firmas.

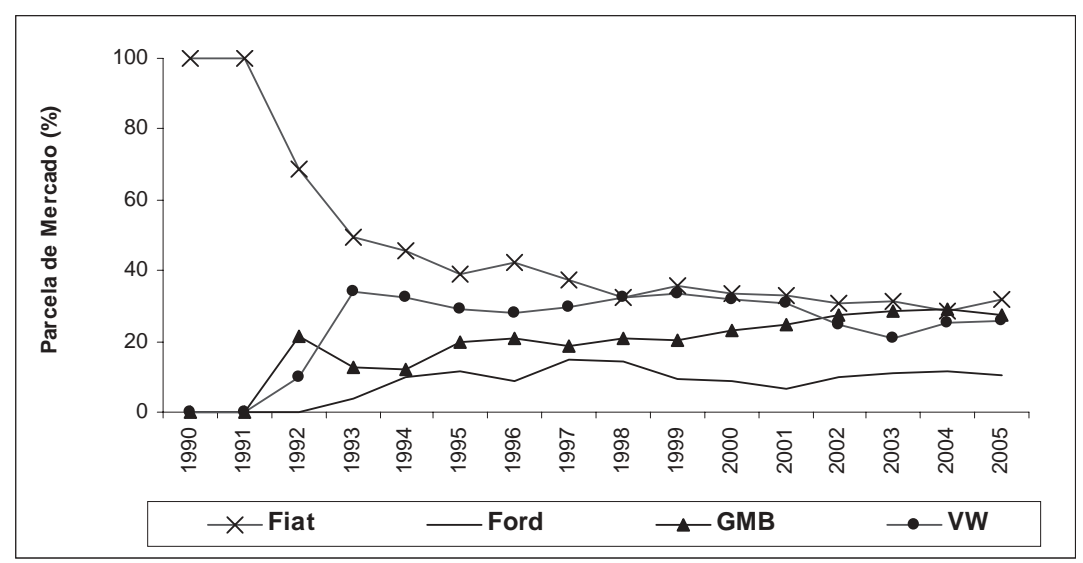

Figura 1 - Evolução da parcela de mercado (em \%) das quatro maiores firmas do mercado brasileiro de automóveis de mil cilindradas, 1990-2005.

Fonte: Resultados da pesquisa.

No período 1990/2005, exceto no ano de 2004, a Fiat deteve a maior parcela de mercado. Por nove anos consecutivos (1993/2001), a VW e a GMB ocuparam a segunda e a terceira posição no ranking, respectivamente. Somente a partir de 2002 houve alternância entre essas duas últimas empresas, com destaque para o ano de 2004, quando a GMB compartilhou com a Fiat a condição de maior vendedora de veículos de mil cilindradas no mercado interno. 
Após determinação das respectivas parcelas de mercado, foram calculados os índices sumários de Herfindahl-Hirschman e as taxas de concentração, com o objetivo de analisar a evolução da concentração do mercado ao longo do período estudado. Por se considerar que o cálculo do CR4 não traria informações relevantes para este trabalho, uma vez que, durante a maior parte do período analisado, havia apenas quatro firmas no mercado, optou-se por trabalhar apenas com o CR2 e o CR3. Os resultados estão apresentados na Tabela 3.

Tabela 3 - Taxas de concentração e índice sumário de HerfindahlHirschman do mercado brasileiro de automóveis de mil cilindradas, 1990-2005

\begin{tabular}{cccc}
\hline Ano & HHI & CR2 & CR3 \\
\hline 1990 & 1,0000 & - & - \\
1991 & 1,0000 & - & - \\
1992 & 0,5266 & 90,02 & 100,00 \\
1993 & 0,3793 & 83,76 & 96,26 \\
1994 & 0,3363 & 77,83 & 89,92 \\
1995 & 0,2919 & 68,36 & 88,30 \\
1996 & 0,3096 & 70,57 & 91,17 \\
1997 & 0,2815 & 66,61 & 85,42 \\
1998 & 0,2742 & 64,77 & 85,84 \\
1999 & 0,2931 & 69,46 & 90,05 \\
2000 & 0,2768 & 65,54 & 88,74 \\
2001 & 0,2730 & 64,27 & 88,87 \\
2002 & 0,2427 & 57,95 & 82,84 \\
2003 & 0,2418 & 60,24 & 81,28 \\
2004 & 0,2449 & 57,77 & 82,78 \\
2005 & 0,2583 & 59,79 & 85,68 \\
\hline
\end{tabular}

Fonte: Resultados da pesquisa.

Os valores dos índices HHI e das taxas de concentração CR2 e CR3, apresentados na Tabela 3, foram importantes para identificar a tendência de desconcentração de mercado, ocorrida ao longo de todo o período. 
O índice HHI, que em 1990 e 1991 era igual a um e representava uma situação de monopólio, foi bruscamente reduzido para 0,5266 já em 1992, o que indica a entrada de novas firmas no mercado. Ao longo do tempo, esse índice decresceu gradativamente, com algumas exceções, quando apresentou aumento pouco significativo, até alcançar o valor de 0,2583 em 2005.

Utilizado para se determinar o número de firmas "iguais" no mercado, o valor de 0,2583 , em 2005, indicou que haveria apenas quatro firmas iguais nesse mercado, o que evidencia forte concentração e facilidade de cooperação entre elas.

Similarmente ao índice HHI, a taxa de concentração CR2 apresentou tendência de queda ao longo do período analisado. Em 1992, as duas maiores firmas - a Fiat e a GMB - detinham cerca de $90 \%$ do mercado interno de veículos de mil cilindradas, enquanto em 2005 esse percentual esteve próximo de $60 \%$. A taxa de concentração CR3 também decresceu ao longo do tempo, embora de maneira menos expressiva que a taxa CR2. Em 2005, as três maiores firmas responderam por cerca de $85 \%$ das vendas desse mercado.

$\mathrm{O}$ fato de o CR2 ter decrescido cerca de 30 pontos percentuais nos anos de 1992 e 2005, enquanto o CR3 decresceu apenas 15 pontos percentuais nesse mesmo período, mostra que a parcela de mercado perdida pelas duas maiores firmas foi, em grande parte, absorvida pela terceira maior.

Seguindo a classificação adotada por Shepherd (1999), a estrutura do mercado brasileiro de carros populares apresenta-se, mesmo após o processo de desconcentração ocorrido ao longo do período 1990/2005, fortemente oligopolizada.

Além da atuação de reduzido número de empresas no mercado interno de carros populares, contribuiu para a concentração desse mercado o fato de nenhum outro país produzir essa categoria de veículos, eliminando, pelo menos no curto prazo, a entrada do produto importado no mercado. 
Segundo Negri (1998), os competidores externos ainda enfrentaram grandes barreiras à entrada, em decorrência de esses automóveis terem sido desenvolvidos especificamente para o mercado brasileiro, apresentando pouca semelhança técnica com os veículos desenvolvidos em outros países.

Em relação às barreiras à entrada, outras fontes puderam ser identificadas. De acordo com Santos et al. (1999), os quatro maiores fabricantes de veículos já instalados no Brasil (Fiat, GMB, Ford e VW) dominam o mercado nacional com produtos em todas as faixas, obtendo, assim, economias de escala e escopo.

Essa vantagem apresentada pelas firmas que já se encontravam no mercado no momento da criação da categoria dos veículos populares foi ratificada pelo estudo de Anderson et al. (1992), que, citados por Fiuza (2002), afirmaram haver, para o mercado de automóveis americano, ganhos de escala em Pesquisa e Desenvolvimento (P\&D), na produção, com promoções e propaganda e também na distribuição do produto.

O estudo "Agências e Anunciantes", publicado pela Meio e Mensagem (2003), mostrou que os quatro maiores produtores nacionais de veículos estiveram entre os dez maiores anunciantes de todos os setores da economia brasileira no ano de $2002^{9}$. A Fiat foi a que mais gastou com propaganda, tendo sido a quarta colocada no ranking nacional, realizando um gasto de R $\$ 98,5$ milhões, enquanto a VW foi, das quatro, a que menos gastou ( $\mathrm{R} \$ 83,75$ milhões), tendo ocupado a décima posição no ranking nacional. A Ford ocupou a quinta posição e a GM, a oitava, com gastos realizados de $\mathrm{R} \$ 91,47$ e $\mathrm{R} \$ 87,12$ milhões, respectivamente ${ }^{10}$.

\footnotetext{
Os gastos com propaganda, apesar de relacionados com Conduta das empresas, são fontes consideráveis de barreiras à entrada e estão positivamente relacionados com mercados mais imperfeitos.

10 Os gastos apresentados são referentes a anúncios feitos em jornais, revistas, TV aberta e por assinatura, rádio e outdoors, sendo que, para TV, foram computadas apenas as inserções durante os intervalos comerciais (Meio e Mensagem, 2003). Não foram considerados outros tipos de despesas de promoção e propaganda, por exemplo, gastos como patrocínios esportivos, de forma que os valores apresentados, certamente, subestimam os gastos realizados pela indústria automobilística.
} 
Outra fonte de barreira à entrada é a participação crescente das empresas desse setor em atividades relacionadas com seu produto. Segundo Santos et al. (1999), é cada vez maior a participação de bancos das montadoras no financiamento para compra de veículos, atualmente responsáveis pela maior parte dos empréstimos concedidos, agilizando as operações e reduzindo custos do crédito. Soma-se ainda a participação das montadoras em companhias de seguros automotivos, o que facilita a concessão de bônus e outros atrativos ao consumidor no momento da venda.

A necessidade de elevadas quantias de capital é, certamente, uma forte barreira à entrada de novas firmas no mercado, confirmada pelos valores apresentados na Conjuntura Econômica (2003). De acordo com tais valores, no ano de 2002, o setor de fabricação e montagem de veículos automotores apresentou um ativo total superior a $\mathrm{R} \$ 8,5$ bilhões, sendo $\mathrm{R} \$ 4,04$ bilhões referentes ao ativo permanente das empresas.

Somente em 2002 foram investidos US\$ 976 milhões na produção nacional de veículos automotores (Anfavea, 2005a), e constatou-se que as principais montadoras trabalham com considerável capacidade ociosa na produção dos veículos. Segundo Calmon (2003), atualmente a indústria nacional chegou a atingir 50\% de capacidade ociosa, uma vez que, apesar de ter condições para produção de 3 milhões de automóveis por ano, só produz cerca de 1,5 milhão.

\section{Conclusões}

Os resultados encontrados neste trabalho mostraram que, apesar de o mercado brasileiro de carros populares ter apresentado tendência de desconcentração ao longo do período 1990/2005, esse mercado ainda se encontra fortemente concentrado.

O reduzido número de firmas contribuiu, sobremaneira, para esse resultado. Da mesma forma, foram encontrados alguns indicadores da presença de barreiras à entrada. Considerando ainda que as firmas não 
sofrem a ameaça da entrada do produto importado, estão dadas as condições que favorecem o exercício coordenado do poder de mercado.

Ressalta-se que os níveis de concentração encontrados certamente seriam menores se a análise fosse realizada não apenas para o segmento dos carros populares, mas abrangendo as demais categorias de veículos automotores. Nessas categorias, o mercado distribui-se por maior número de firmas e há maior presença do produto importado.

É importante deixar claro que este estudo não pretendeu atribuir à concentração do mercado a responsabilidade integral pelo comportamento dos preços dos carros populares. Entretanto, ele fornece subsídios que favorecem o melhor conhecimento desse mercado. Seria um grande equívoco desprezar os efeitos das mudanças ocorridas na engenharia desses veículos, ao longo do período estudado, sobre seus preços ${ }^{11}$.

Fica a sugestão de um acompanhamento próximo desse mercado por parte da Secretaria de Acompanhamento Econômico (SEAE) e da Secretaria de Defesa Econômica (SDE), uma vez que os indicadores de concentração encontrados se enquadram na faixa considerada por esses órgãos como suficiente para o exercício coordenado do poder de mercado.

\footnotetext{
11 Algumas dessas mudanças são, por exemplo, a criação de motores bicombustível, mais potentes e mais eficientes no consumo de combustível; a participação crescente dos veículos com quatro portas no total das vendas; e itens que trazem maior conforto e segurança ao consumidor, como o acionamento elétrico dos vidros e das travas das portas, sistema hidráulico de direção, entre outros.
} 


\section{Referências}

AGUIAR, D. R. D. Organização Industrial: O paradigma estruturaconduta-desempenho e a escola de Chicago. Viçosa, 2003. Mimeografado.

ANDERSON, P.; PALMA, A.; THYSSE, J. F. Discrete choice theory of product differentiation. Cambridge, M.A.: MIT Press, 1992.

ANFAVEA. Anuário Estatístico da Indústria Automobilística Brasileira - 2005. 2005a. Disponível em: 〈http://www.anfavea.com.br $>$. Acesso em: 12 mar. 2006.

Automóveis 1000cc: vendas internas no atacado por modelo e combustível e participação nas vendas de automóveis nacionais. 2004. Disponível em: <http://www.anfavea.com.br/tabelas2004/ VDPOP04.xls>. Acesso em: 16 mar. 2006.

Automóveis 1000cc: vendas internas no atacado por modelo e combustível. 2005b. Disponível em: <http://www.anfavea.com.br/ tabelas2005/autoveiculos/VDPOP05.xls>. Acesso em: 16 mar. 2006.

CALMON, F. Revista Alta Roda. Mar. 2003. Disponível em: <http:// www.automotivebusiness.com.br/carropopular.htm>. Acesso em: 19 ago. 2005 .

COATES, M. V. Política de crédito ao consumidor e desempenho do setor industrial: uma análise da experiência brasileira, 1972-1981. Rio de janeiro: PUC-RJ, 1985. Dissertação de Mestrado - Pontifícia Universidade Católica do Rio de Janeiro, 1985.

CONJUNTURA ECONÔMICA. As 500 maiores sociedades anônimas do Brasil: classificação geral. Rio de Janeiro: Fundação Getúlio Vargas, v. 57, n. 08, ago. 2003. 
FIUZA, E. P. S. Automobile Demand and Supply in Brazil: effects of tax rebates and trade liberalization on price-marginal cost Markups in the 1990s. Rio de Janeiro: IPEA, 2002. (Texto para Discussão, n. 916).

LEVINSOHN, J. Empirics of taxes on differentiated products: the case of tariffs in the U.S. automobile industry. Chicago: University of Chicago Press, 1988.

MARTIN, S. Industrial Economics. Blackwell Publisher. [S.I.:s.n], 1993.

McCARTHY, P.S. Market price and income elasticities of new vehicle demands. The Review of Economics and Statistics, aug. 1996.

MEIO \& MENSAGEM. Agências e Anunciantes. Jun. 2003. Disponível em: 〈http://www.mmonline.com.br〉. Acesso em: 18 ago. 2005.

NEGRI, J. A. Elasticidade-Renda e Elasticidade-Preço da Demanda de Automóveis no Brasil. Brasília: IPEA, 1998. (Texto para Discussão, n. 558).

SANTOS, A. M. M. M.; PINHÃO, C. M. M.; CROESY, L. C. Distribuição do Mercado de Veículos Leves. Brasília: BNDES, 1999. Estudos Setoriais - Complexo Automotivo, n. 28. Disponível em: <http:// www.bndes.gov.br/conhecimento/setorial/get2is28.pdf >. Acesso em: 14 set. 2005 .

SHEPHERD, W. G. The Economics of Industrial Organization. Illinois: Waveland Press, 1999. 447 p. 


\begin{abstract}
The objective of this paper was to analyze the evolution of the Structure of the Brazilian market of popular cars in the period from 1990 to 2005. Information on the number of units sold by each firm in the domestic market have been used to determine each firm's market-share, levels of concentration and the HerfindahlHirschman Index. The results have pointed that, although reduction in the concentration of this market during the period have occurred, the market is still strongly concentrated according to the levels established by the Office of Economic Investigation (SEAE) and by the Office of Economic Defense (SDE) for the exercise of the coordinated market power.
\end{abstract}

Key words: industrial organization, market structure popular cars. 